2. Brady PG (1978); "Gastric phytobezoars consequent to delayed gastric emptying"; Gastrointest.Endosc. 1978:25:159-61.

3. Benes J (1991); "Treatment of gastric bezoars by extracoporeal shock wave lithotripsy"; Endoscopy 1991;23:346-348.

4. Harris R.Clearfield (1995); "Trauma, Bezoars, and other Foreign Bodies". Gastroenterology 5th editon, W.B.Saunder Company 1995.

5. Marios Pouagare, Patrick G.Brady (1994) "New techniques for the endoscopic removal of foreign bodies"; Advanced therapeutic endoscopy. Raven Press-New York.
6. Park SE, Ahn JY, Juna HY, Na S, Park SJ, Lim H, Choi KS, Lee JH, Kim DH, Choi KD, Sona HJ, Lee $\mathrm{GH}$, Kim JH: "Clinical outcomes associated with treatment modalities for gastrointestinal bezoars". Gut Liver. 2014;8(4):400.

7. Robert S.Sandler, Andrea Todisco (1999); "Gastric bezoars"; Gastroenterolory. Lippinton William\&Wilkin, 1999.

8. Soehendrea N (1989); "Endoscopic removal of trichobezoars", Endoscopy 1989;21:201-207.

9. Y.G.Wang, U.Seitz, Z.L.Li (1998); "Endoscopic management of huge bezoars", Endoscopy $1998 ; 30: 371-374$

\title{
ĐÁNH GIÁ CHỨC NĂNG TIỀN ĐÌNH BẰNG NGHIỆM PHÁP NHIỆT TRONG BÊ̂NH U THẦN KINH THÍNH GIÁC
}

\section{TÓM TẮT}

Mục tiêu: Đánh giá chức năng tiền đình ở bênh nhân ư thần kinh thính giác bằng nghiệm pháp nhiệt. Đối tượng và phương pháp: Nghiên cứu mô tả cắt ngang 50 bệnh nhân (19 nam và 31 nữ, tuổi từ 16 đến 71 năm), được chẩn đoán u thần kinh thính giác (48 bênh nhân có u một bên và 2 bệnh nhân có u ở hai bển), được đánh giá chức năng tiền đình bằng nghiêm pháp nhiêt với nước ấm $44^{\circ} \mathrm{C}$ và nước lanh $30^{\circ} \mathrm{C}$. Kết quả: Tỷ lệ đáp ứng của tai có u với nước ấm là 5,8\% (3/52 tai), với nước lanh là $11,5 \%(6 / 52$ tai), của tai không có u tương ứng là $85,4 \%$ (41/48 tai) và $95,8 \%(46 / 48$ tai) $(\mathrm{p}<0,001)$. Giảm đáp ứng tiền đình một bên chiếm $88 \%$ (44/50 bệnh nhân), đều găp ở bênh nhân u môt bên. Cả hai bênh nhân có u ở hai bên không biểu hiện giảm đáp ứng tiền đình một bên. Tỷ lê bênh nhân có giảm đáp ứng tiền đình mồt bên > $22 \%$ là $90 \%(9 / 10)$ ở nhóm u vữa, ở nhóm u to là $86,7 \%(13 / 15)$, và $88,0 \%(22 / 25)$ ở nhóm u khổng lồ $(p=0,746)$. Kết luận: Đa số bệnh nhân u thần kinh thính giác bi giảm và mất chức năng tiền đình ở tần số rất thấp, không phụ thuộc vào kích thước khối u.

Từ khoá: u thân kinh thính giác, nghiệm pháp nhiệt

\section{SUMMARY}

ASSESSMENT OF THE VESTIBULAR FUNCTION IN ACOUSTIC NEUROMA BY CALORIC TEST

Objectives: To evaluate the vestibular function in patients with acoustic neuromas by caloric test. Patients and methods: A cross-sectional study was conducted on 50 patients (19 men and 31 women, aged 16 to 71 years), who were diagnosed with

\section{${ }^{1}$ Bênh viện Bach Mai}

${ }^{2}$ Trường Đai hoc Y Hà Nôi

Chịu trách nhiệm chính: Đào Trung Dũng

Email: daotrungdung@hmu.edu.vn

Ngày nhận bài: 5.01 .2021

Ngày phản biên khoa hoc: 2.3.2021

Ngày duyệt bài: 12.3.2021
Đào Trung Dũng ${ }^{1,2}$

acoustic neuromas (48 patients with unilateral tumors and 2 patients with tumor on both sides), and were assessed their vestibular function by caloric test with warm water $\left(44^{\circ} \mathrm{C}\right)$ and cold water $\left(30^{\circ} \mathrm{C}\right)$. Results: The response rate of the ears with tumors to warm water was $5.8 \%$ ( 3 of 52 ears), with cold water was $11.5 \%$ (6 of 52 ears), lower than that of the ears without tumors were $85.4 \%$ ( $41 / 48$ ears) and $95.8 \%$ (46/48 ears), respectively ( $p<0.001)$. Unilateral weakness accounted for $88 \%$ (44 of 50 patients) in all patients with unilateral tumors. In contrast, the two patients with bilateral tumors did not exhibit unilateral weakness. The proportion of patients with unilateral weakness over $22 \%$ was $90 \%$ (9 of 10 patients) in the medium tumor group, in the large tumor group was $86.7 \%$ (13 of 15 patients), and $88.0 \%$ (22 of 25 patients) in giant tumors group $(p=0.746)$ Conclusions: The majority of patients with acoustic neuromas had their vestibular function decreased and lost at a very low frequency, regardless of tumor size.

Keywords: acoustic neuroma, caloric test

\section{I. ĐĂTT VẤN ĐỀ}

U thần kinh thính giác (TKTG) là u tế bào schwann lành tính, trong đa số trường hợp xuất phát từ dây thần kinh tiền đình trên và dưới. ${ }^{1} \mathrm{Khi}$ khối u còn nhỏ ảnh hưởng chủ yếu lên chức năng nghe và thăng bằng, tuy nhiên nếu $u$ đat kích thước đủ lớn sẽ chèn ép lên thân não, tiểu não, gây tăng áp lực nội sọ và dẫn đến biến chứng nguy hiểm.

Nghiệm pháp nhiệt là phương pháp đánh giá chức năng mào bóng của ống bán khuyên ngoài và phản xạ tiền đình mắt ở tần số rất thấp $(0,004 \mathrm{~Hz})$ bằng cách bơm nước hoặc khí có nhiêt đô khác với nhiệt đô̂ cơ thể vào ống tai ngoài. ${ }^{2,3}$ Nhiệt lượng truyền qua tai giữa đênn ống bán khuyên ngoài, gây ra hiệu ứng nhiệt làm di chuyển nội dịch dẩn đến phản xạ động mắt ngang. Dựa trên đáp ứng động mắt có thể nhận 
định được chức năng tiền đình bên tai được kích thích là bình thường hay bất thường. Vì vậy, đây là một trong những biện pháp chẩn đoán quan trọng đối với đánh giá chức năng tiền đình, trong đó có bênh u thần kinh thính giác.

Nghiên cứu này được tiến hành nhằm tìm hiểu chức năng tiền đình ở bênh nhân u thần kinh thính giác bằng nghiệm pháp nhiệt.

\section{II. ĐỐI TƯợNG VÀ PHƯƠNG PHÁP NGHIÊN CỨU}

Nghiên cứu mô tả cắt ngang 50 bệnh nhân (19 nam và 31 nữ, tuổi từ 16 đến 71 năm), được chẩn đoán u TKTG tại Trung tâm Phẫu thuật thẩn kinh, Bệnh viện hữu nghị Việt Đức trong khoảng thời gian từ tháng 9/2012 đến tháng 5/2016. Tiêuu chuẩn lựa chọn gồm có bệnh nhân chưa phẫu thuật lần nào, vận động nhãn cầu bình thường, không bi mất ý thức, được làm nghiêm pháp nhiệt với nước ấm $44^{\circ} \mathrm{C}$ và lạnh $30^{\circ} \mathrm{C}$. Tiêu chuẩn loại trừ là bệnh nhân thủng màng nhĩ.

Kích thước khối u dựa trên đường kính lớn nhất đo được của phần u trong góc cầu tiểu não trên phim cộng hưởng từ so não có tiêm thuốc đối quang từ,, theo hướng dấn của Hội nghị đồng thuận về các hệ thống báo cáo kết quả đối với u TKTG (u khu trú ở ống tai trong, u nhỏ: 1-10 $\mathrm{mm}$, u vừa: $11-25 \mathrm{~mm}$, u to: $26-40 \mathrm{~mm}$, u khổng lồ: > $40 \mathrm{~mm}){ }^{1}$

Quy trinh làm nghiệm pháp nhiệt. Trong vòng $24 \mathrm{~h}$, bênh nhân không sử dụng các thuốc an thần, gây ngủ hay kháng histamin $\mathrm{H} 1$. Bệnh nhân được làm sạch ống tai ngoài, nằm ngửa trên giường khám, đầu nâng cao 30 độ, đeo kính Frenzel. Bơm lần lướt vào ống tai ngoài từng bên mỗi lần $250 \mathrm{ml}$ nước (ấm $44^{\circ} \mathrm{C}$ và lạnh $30^{\circ} \mathrm{C}$ được đo bằng nhiệt kế thuỷ ngân) trong vòng 30 giầy theo thứ tự phải âm, trái ấm, phải lạnh, trái lanh, cách nhau 5 phút. ${ }^{2}$ Trong trường hợ không có động mắt xuất hiện với cả nước ẩm $44^{\circ} \mathrm{C}$ và lạnh $30^{\circ} \mathrm{C}, 2 \mathrm{ml}$ nước $10^{\circ} \mathrm{C}$ sẽ được bơm vào ống tai trong vòng 20 giây để khẳng định tiền đình đã mất hoàn toàn đáp ứng hay chưa. ${ }^{2}$ Ghi nhận thời gian tiềm tàng (bắt đầu bơm nước đến khi xuất hiện động mắt) và thời gian động mắt (bắt đầu động mắt đên khi hết, trong đó WR và WL lần lượt là thời gian động mắt khi bơm nước ấm vào tai phải và tai trái, $\mathrm{CR}$ và $\mathrm{CL}$ lần lượt là thời gian động mắt khi bơm nước lạnh vào tai phải và tai trái). Dựa trên thời gian động mắt (giây) để tính chỉ số giảm đáp ứng tiền đình một bên (Unilateral Weakness - UW) theo công thức của Jongkees².

$$
\mathrm{UW}=\frac{(W R+C R)-(W L+C L)}{W R+C R+W L+C L} \times 100
$$

Chẩn đoán giảm đáp ứng tiền đình một bên khi UW > 22\%, phân loại mức độ giảm đáp ứng tiền đình một bên theo phân loại của Teggi (Loại A: < $25 \%$, loại B: $25-50 \%$, loại C: $50-75 \%$, loại D: $>75 \%)^{4}$

Kết quả được xử lí bằng phần mềm SPSS 16.0 (SPSS Inc., Chicago, Illinois), sử dụng khi bình phương với kiểm định hai phía nhằm so sánh các tỷ lệ. Sự khác biệt có ý nghĩa thống kê với $\mathrm{p}<0,05$.

\section{KẾT QUẢ NGHIÊN CỨU}

Trong số 50 bênh nhân được chẩn đoán u thần kinh thính giác, có 48 trường hợp u ở một bên và 2 trường hợp u ở hai bên.

Tỷ lệ đáp ứng với nước ấm $44^{\circ} \mathrm{C}$ của bên tai có u là $3 / 52(5,8 \%)$ thấp hơn so với bên tai không có u là $41 / 48(85,4 \%)(p<0,001)$. Tỷ lệ đáp ứng với nước lạnh $30^{\circ} \mathrm{C}$ của bên tai có u là $6 / 52(11,5 \%)$ thấp hơn so với bên tai không có u là $46 / 48(95,8 \%)(p<0,001)$ (Bảng 1$)$.

Bảng 1. Kêt quả tai có đáp ứng với nghiệm pháp nhiệt

\begin{tabular}{|c|c|c|c|c|c|}
\hline \multirow{2}{*}{$\begin{array}{c}\text { Nghiệm } \\
\text { pháp }\end{array}$} & \multicolumn{2}{|c|}{$\begin{array}{c}\text { Tai có u } \\
(\mathbf{n}=\mathbf{5 2})\end{array}$} & \multicolumn{2}{|c|}{$\begin{array}{c}\text { Tai không có } \\
\mathbf{u}(\mathbf{n}=\mathbf{4 8})\end{array}$} & \multirow{2}{*}{$\mathbf{p}$} \\
\cline { 2 - 5 } & $\mathbf{n}$ & $\mathbf{\%}$ & $\mathbf{n}$ & $\mathbf{\%}$ & \\
\hline $\begin{array}{c}\text { Nước ấm } \\
44^{\circ} \mathrm{C}\end{array}$ & 3 & 5,8 & 41 & 85,4 & 0,001 \\
\hline $\begin{array}{c}\text { Nước } \\
\text { lạnh } 30^{\circ} \mathrm{C}\end{array}$ & 6 & 11,5 & 46 & 95,8 & 0,001 \\
\hline
\end{tabular}

Giảm đáp ứng tiền đình một bên gặp với tỷ lệ $88,0 \%$ (44/50 bệnh nhân), đều gặp ở những bệnh nhân có khối u ở một bên, trong đó đa số là loại $D$ với tỷ lệ $84 \%$ (42/50 bệnh nhân), loại $B$ và $C$ đều có tỷ lệ $2 \%$ (1/50 bểnh nhân) (Bảng 2). Cả hai bệnh nhân u ở hai bên đều nằm trong số 6 bệnh nhân không có biểu hiện giảm đáp ứng tiền đình một bên (loại $A$ ).

Bảng 2. Chí số giảm đáp ứng tiền đình một bên của 50 bệnh nhân

\begin{tabular}{|c|c|c|}
\hline $\begin{array}{c}\text { Giảm đáp ứng tiền } \\
\text { đình một bên }\end{array}$ & $\mathbf{n}$ & $\mathbf{\%}$ \\
\hline Loại $\mathrm{A}(<25 \%)$ & 6 & 12,0 \\
\hline Loại $\mathrm{B}(25-50 \%)$ & 1 & 2,0 \\
\hline Loại C $(50-75 \%)$ & 1 & 2,0 \\
\hline Loại $\mathrm{D}(75-100 \%)$ & 42 & 84,0 \\
\hline Tống số & $\mathbf{5 0}$ & $\mathbf{1 0 0 , 0}$ \\
\hline
\end{tabular}

Giảm đáp ứng một bên có giá trị chẩn đoán (UW > 22\%) chiếm tỷ lệ $90 \%(9 / 10)$ ở nhóm u vừa, ở nhóm u to là $86,7 \%(13 / 15)$, ở nhóm u khống lồ là 88,0\% (22/25). Sự khác biệt không có ý nghĩa thống kê với $p=0,746$ (Bảng 3). Hai bệnh nhân có khối u ở hai bên (một ở nhóm u vừa và một ở nhóm u to) đều có kết quả giảm 
đáp ứng tiền đình một bên UW = 0 (Loại $A)$.

Bảng 3. Đối chiếu giảm đáp ứng tiền đình một bên với kích thước khối u

\begin{tabular}{|c|c|c|c|}
\hline $\begin{array}{c}\text { Giảm đáp ứng } \\
\text { một bên }\end{array}$ & U vừa & U to & $\begin{array}{c}\text { U khống } \\
\text { iố }\end{array}$ \\
\hline Loại $A(<25 \%)$ & 1 & 2 & 3 \\
\hline Loại B $B(25-50 \%)$ & 0 & 0 & 1 \\
\hline Loại C (50-75\%) & 1 & 0 & 0 \\
\hline Loại $\mathrm{D}(75-100 \%)$ & 8 & 13 & 21 \\
\hline Tống số & $\mathbf{1 0}$ & $\mathbf{1 5}$ & $\mathbf{2 5}$ \\
\hline
\end{tabular}

\section{BÀN LUẬN}

Nghiệm pháp nhiệt cho phép đánh giá chức năng của tiền đình từng bên ở tần số rất thấp $(0,004 \mathrm{~Hz})$, giúp phát hiện những tổn thương tiến triển từ từ khi kết quả của các nghiệm pháp khác bình thường do hiện tượng bù trừ. Mặc dù chỉ cho biết hoạt động của ống bán khuyển và dây thần kinh tiền đình trên, đây vẫn là một thăm dò chức năng quan trọng trong chẩn đoán các rối loạn chức năng tiền đình, đặc biệt là đối với u TKTG.

Đáp ứng với nghiệm pháp nhiệt của tai có u là $5,8 \%$ với nước ấm $44^{\circ} \mathrm{C}$ và $11,5 \%$ với nước lannh $30^{\circ} \mathrm{C}$, thấp hơn rất nhiều so với tỷ lệ tương ứng của tai không có u là $85,4 \%$ với nước ấm và $95,8 \%$ với nước lạnh (Bảng 1 ). Theo y văn, đây hậu quả của tổn thương trên dây thần kinh tiền đình trên do khối u đè ép hoặc vi xâm lấn trực tiếp lên các sợi trục gây ra nghẽn dẫn truyền xung động thần kinh từ mào bóng của ống bán khuyên ngoài về thân não. ${ }^{3}$ Trong nghiên cứu 130 bệnh nhân u TKTG, Suzuki nhận thấy không có sự khác biệt có ý nghĩa về đáp ứng với nghiệm pháp nhiệt khi u xuất phát từ dây thần kinh tiền đình trển và dây thần kinh tiền đình dưới. ${ }^{5}$ Bên cạnh đó, mất đáp ứng với nghiệm pháp nhiệt còn có thể là hậu quả của tổn thươning tai trong do khối u chèn ép động mạch tai trong dẫn đến thiếu máu nuôi dưỡng mê nhĩ, trong đó có ống bán khuyên ngoài là nơi đầu tiên nhận kích thích nhiệt. ${ }^{3}$ Theo Batuecas-Caletrio, tỷ lệ không đáp ứng với nghiệm pháp nhiệt tăng có ý nghĩa khi khối u có kích thước từ $20 \mathrm{~mm}$ trở lên. ${ }^{6}$ Vì thế, mặc dù chỉ mang tính định tính (có hoăc không), nhứng khi kết quả của nghiệm pháp nhiệt trả lời tai không đáp ứng thì rất có giá trị gợi ý có tổn thương mê nhĩ hoặc sau mê nhĩ, từ đó chỉ định tiến hành các thăm dò chuyên sâu hơn như chụp cộng hưởng từ sọ não hoặc cắt lớp vi tính.

Nghiên cứu chỉ ra $88 \%$ BN có biểu hiên giảm đáp ứng tiền đình một bên trong đó chủ yếu là mức độ nặng loại $D(84 \%)$, loại $B$ và $C$ ít gặp (đều là $2 \%$ ) (Bảng 2). Kết quả trên tương đônng với Tringali là $86 \%,{ }^{3}$ thấp hơn Berrettini là $92,3 \%,{ }^{7}$ nhưng cao hơn Kentala là $66 \% .^{8}$ Theo một số tác giả, mức độ giảm đáp ứng đối với nghiệm pháp nhiêtt tương quan thuận với kích thước khối u; đối với những khối u có đường kính $>20 \mathrm{~mm}$ thì tỷ lệ giảm đáp ứng tiền đình một bên có thể tăng đến $93 \% .^{9}$ Đặc biệt, chỉ số giảm đáp ứng tiền đình một bên có tính định lượng, giúp thể hiện rõ được sự khác biệt giữa hai tai, đặc biệt cho những trường hợp bên tai có khối u vấn còn đáp ứng. Mặt khác, trong nghiên cứu của chúng tôi giá trị giảm đáp ứng tiên đình một bên dưới 22\% gặp ở 6 bệnh nhân, trong đó 4 trường hợp là u một bên và 2 có u ở cả hai bên u hai bên. Điều này chứng tỏ chỉ số giảm đáp ứng tiền đình một bên rất có giá trị khi bất thường (UW > 22\%), còn nếu dưới $22 \%$ thì không kết luận được (có thể không có u, u hai bên hoặc u một bên nhưng đã có bù trừ trung ương) mà cần phối hợp với các chỉ số thăm dò khác.

Kết quả nghiên cứu còn cho thấy giảm đáp ứng tiền đình một bên có giá trị chẩn đoán (UW $>22 \%$ ) gặp với tỷ lệ $90 \%$ với nhóm u vừa, ở nhóm u to là $86,7 \%$, và $88 \%$ u khổng lồ, trong đó chủ yếu là giảm mức độ nặng (UW > 75\%) với $80 \%$ ở u vừa, ở nhóm u to là $86,7 \%$, và $84 \%$ với u khổng lồ (Bảng 3). Mặc dù khác biệt về cách phân độ khối u, kết quả nghiên cứu của chúng tôi tương đồng với Berrettini có tỷ lệ giảm đáp ứng với nghiệm pháp nhiệt là $80 \%$ với u nhỏ $(1-10 \mathrm{~mm}), 88,9 \%$ u vừa $(10-30 \mathrm{~mm})$ và $100 \%$ u to (đường kính > 30mm). ${ }^{7}$ Cơ chế của giảm đáp ứng tiền đình một bên được cho là hậu quả của sự phối hợp tổn thương trực tiếp dây thân kinh tiền đình và gián tiếp ở mê nhĩ do khối u chèn ép gây thiếu máu động mach tai trong. ${ }^{3}$ Theo Hulshof, giảm đáp ứng tiền đình một bên với nghiệm pháp nhiệt xảy ra rõ rệt đối với những khối u có đường kính trên $20 \mathrm{~mm} .{ }^{10}$ Như vậy, ưu điểm của chỉ số giảm đáp ứng tiền đình một bên là so sánh thời gian động mắt với kích thích nhiệt ấm và lạnh giữa hai bên tai, giúp phát hiện sớm bất thường ngay cả khi bên tai có khối u vẫn còn đáp ứng và khối u chưa to.

\section{KẾT LUẬN}

Đa số bệnh nhân u thần kinh thính giác bị giảm và mất chức năng tiền đình ở tần số rất thấp, không phụ thuộc vào kích thước khối u. Trên lâm sàng, cần phối hợp cả đánh giá định tính dựa trên có hay không đáp ứng của tai được kích thích nhiệt và định lượng dựa trên chỉ sô giảm đáp ứng tiền đình một bên để tăng khả năng phát hiện rối loạn chức năng tiền đình. 
TÀI LIÊU THAM KHẢO

1. Kanzaki J, Tos M, Sanna M. Acoustic Neuroma: Consensus on Systems for Reporting Results. Tokyo: Springer; 2003.

2. Mccaslin Electronystagmography/Videonystagmography. San Diego: Plural Publishing; 2013:147-174.

3. Tringali $S$, Charpiot $A$, Ould $M$, al. e. Characteristics of 629 vestibular schwannomas according to preoperative caloric responses. Otology \& Neurotology. 2010;31:467-472.

4. Yingling $C D$, Gardi JN. Intraoperative monitoring of facial and cochlear nerves during acoustic neuroma surgery. 1992. Neurosurg Clin N Am. Apr 2008;19(2):289-315, vii.

5. Gerganov $V$, Nouri $M$, Stieglitz $L$, al. e. Radiological factors related to pre-operative hearing levels in patients with vestibular schwannomas. Journal of Clinical Neuroscience. 2009; 16:1009-1012.

6. Tos M, Thomsen J, Harmsen A. Results of translabyrinthine removal of 300 acoustic neuromas related to tumour size. Acta otolaryngologica. 1988;105(sup452):38-51.

7. Berrettini S, Ravecca F, Sellari-Franceschini S, al e. Acoustic neuroma: correlations between morphology and otoneurological manifestations. Journal of the Neurological Sciences 1996;144:24-33.

8. Kentala E, Pyykko I. Clinical picture of vestibular schwannoma. Auris Nasus Larynx,. 2001;28:15-22.

9. Wang AY, Wang JT, Dexter $M$, al. e. The vestibular schwannoma surgery learning curve mapped by the cumulative summation test for learning curve. Otol Neurotol. 2013;34(8):1469-1475.

\title{
ĐĂC ĐIỂM LÂM SÀNG BÊ̂NH VIÊM LỢI TRÊN PHỤ NỮ CÓ THAI TẠI KHOA SẢN BỆNH VIÊ̂N BẠCH MAI, NĂM 2019-2020
}

\author{
Phan Huy Hoàng ${ }^{1}$, Hoàng Bảo Duy ${ }^{1}$, \\ Hà Ngọc Chiều ${ }^{1}$, Trịnh Thị Thái Hà ${ }^{1}$, Lê Hưng ${ }^{2}$
}

\section{TÓM TẮT}

Mục tiêu: Nhân xét đặc điểm lâm sàng bênh viêm Iợi trên phu nữ có thai tại khoa sản bênh viện Bach Mai - Hà Nồi năm 2019-2020. Phương pháp nghiên cứu: mô tả cắt ngang. Kết quả: phu nữ mang thai chủ yếu mắc viêm lợi mức độ $2(93,6 \%)$. Mức độ viêm lợi với chỉ số GI và mức độ mảng bám với chỉ số PI tăng dần theo tuổi thai. Mức độ viêm lợi cũng tăng theo tuổi phu nữ mang thai. Mức đô viêm lợi ở nhóm răng phía trước (chỉ số $\mathrm{GI}=1,52$ ) nặng hớn so với nhóm răng phía sau (chỉ số GI $=1,25$ ). Kết luân: Hầu hết phụ nữ mang thai bị viêm lợi. Cần tẳng cường, lồng ghép kiến thức chăm sóc sức khoẻ răng miệng vào chương trình chăm sóc sức khỏe sinh sản và cần có những nghiên cứu sâu hơn, rộng hơn về bệnh lý viêm lợi, viêm nha chu trên phụ nữ mang thai để khẳng định và đưa ra các biên pháp dự phòng.

Tư khoá: Viêm lợi, phụ nữ có thai.

\section{SUMMARY}

\section{CLINICAL CHARACTERISTICS OF GINGIVITIS IN PREGNANT WOMEN AT THE OBSTETRICS OF BACH MAI HOSPITAL, 2019-2020}

Objective: To comment on the clinical characteristics of gingivitis in pregnant women at the obstetric department of Bach Mai hospital - Hanoi in 2019-2020. Research method: cross-sectional

${ }^{1}$ Viện Đào tạo Răng Hàm Mặt,Trường Đại học Y Hà Nội ${ }^{2}$ Bệnh viện Đa khoa Đống Đa

Chiu trách nhiệm chính: Phan Huy Hoàng

Email: Nhasixman@gmail.com

Ngày nhận bài: 6.01.2021

Ngày phản biện khoa học: 4.3.2021

Ngày duyệt bài: 15.3.2021 description. Results: Mainly, pregnant women had degree 2 gingivitis (93.6\%). The level of gingivitis with GI and plaque levels with PI increases gradually with gestational age. The level of gingivitis also increases by the age of the pregnant woman. The level of gingivitis in the anterior teeth (GI index $=1.52$ ) was found heavier than that of the posterior ones (GI index $=1.25)$. Conclusion: Most pregnant women suffer gingivitis. It is necessary to strengthen and integrate knowledge of oral health care into the reproductive health care program and conduct deeper and broader studies on gingivitis and periodontitis in pregnant women to confirm and propose preventive measures.

Keywords: Gingivitis, pregnant women.

\section{I. ĐắT VẤN ĐỀ}

Bê̂nh vùng quanh răng là một trong những bệnh phổ biến trong các bệnh răng miệng. Bệnh gặp ở mọi lứa tuổi, mọi quốc gia trên thế giới, chiếm tỷ lê cao trong cộng đồng và mang tính chất xã hôi. Bênh không chỉ gây tổn thương tai chố mà còn ảnh hưởng đến sức khỏe toàn thân và thẩm mỹ của người bệnh. Năm 1986, WHO xếp bệnh quanh răng là hiểm hoa thứ 3 của loài người sau các bênh ung thư, tim mạch. Bênh cũng đã được nhiều tác giải nghiên cứu và chứng minh có mối liên quan với tình trạng sinh non, nhẹ cân thiếu tháng ở phụ nữ mang thai [1],[2].

Viêm lợi là một bệnh lý phổ biến trong nhóm bệnh quanh răng, đây là tổn thương ở giai đoạn khởi đâu và khu trú ở lợi mà chưa thâm nhập vào tổ chức khác của vùng quanh răng. Ở nước ta, theo kết quả điêuu tra sức khỏe răng miệng 